\title{
You're Skating on Native Land: Queering and Decolonizing Skate Pedagogy
}

\author{
Noah Romero \\ University of Auckland \\ noah.romero@auckland.ac.nz
}

\begin{abstract}
This paper draws from a new materialist interpretation of Maya Angelou's Caged Bird to analyze how Queer and Indigenous skateboarders develop critical and community-responsive ways of knowing and being. This analysis is contrasted with the implications of skateboarding's Olympic debut to theorize how non-dominant groups build self-supporting enclaves in spite of concerted efforts to regulate and exclude them from public life. Skateboarding is herein conceptualized as a critical pedagogy which enables participants to reclaim space, achieve selfdefined learning goals, and challenge the authority of oppressive institutions built upon what Angelou calls "the grave of dreams."
\end{abstract}

Keywords: Skateboarding, decolonization, new materialism, queer theory

\section{Introduction}

Maya Angelou's Caged Bird is imbued with the desperate anger of the oppressed, as emphasized in the poem's second stanza:

But a bird that stalks / down his narrow cage / can seldom see through / his bars of rage / his wings are clipped and / his feet are tied / so he opens his throat to sing...

The caged bird's imprisonment is unjust, its suffering is undeniable, and any outcome other than its liberation is unacceptable. But new materialism, a philosophy that privileges the entanglement of matter and discourse over strictly human concerns (Barad, 2007), compels us to think deeper about the implications of Caged Bird. While the caged bird sings of freedom, new materialism asks what freedom is, where it comes from, and what it costs.

Angelou contrasts the caged bird's squalor with the ostensibly carefree life of the free bird:

A free bird leaps / on the back of the wind / and floats downstream / till the current ends / and dips his wing / in the orange sun rays / and dares to claim the sky...

This stanza combines active verbs (leaps, floats and dips) with descriptions of natural wonder-flowing currents of wind and "orange sun rays." Angelou creates this joyful scene only to trouble it by revealing that the free bird claims all of this wonder for himself. This revelation suggests that the free bird is something of a conqueror, one who believes in his right to assert ownership over nothing less than the sky. The caged bird's cries for "things unknown" invite the reader to wonder if it truly wishes to join the free bird. Having been imprisoned and maimed, perhaps the caged bird yearns to live in a world where such suffering will not be inflicted on

Cultural and Pedagogical Inquiry, Summer 2020, 12(1), pp. 230-243

ISSN 1916-3460 (C) 2020 University of Alberta

http://ejournals.library.ualberta.ca/index.php/cpi/index 
anyone else - one where it is at peace with the sky instead of embroiled in a narcissistic campaign to claim dominion over it.

This reading parallels Freire's (1970) assertion that education is not a process of acquiring the credentials needed to participate in an exploitative society. A liberatory pedagogy is instead inseparable from the need to establish kinder societal frameworks altogether. This article explores how skate pedagogy, or the educative dimension of skateboarding, is an example of one such framework as it fosters community-responsive and antiauthoritarian approaches to teaching and learning. By applying new materialist theory to the study of skate pedagogy in Queer and Indigenous communities, this analysis demonstrates how discourses such as heteronormativity and white supremacy can be challenged even when they are enshrined in law. Still, skateboarding is a contested space and Queer and Indigenous skate pedagogies are emerging alongside a new means of control and confinement - the proposed summer, 2020 Olympic Games.

\section{A History of Skate Culture}

Skateboarding was popularized by American surfers in the 1960s who wanted to practice their sport in the off-season (International Olympic Committee, 2017). Despite its recreational beginnings, skateboarding soon became associated with antiauthoritarian philosophies and politics, which were entangled with those of punk rock. Both subcultures center oppositional orientations toward mainstream norms, do-it-yourself approaches to problem-solving, and the belief that growth is the sole responsibility of the individual (Dinces, 2011; Romero, 2016, 2018, 2020). The oppositional philosophy of skate culture is evident in its iconography - shirts and boards emblazoned with slogans like Skate and Destroy, Skateboarding is Not a Crime, and This Toy Kills Fascists.

Skateboarding's rebellious ontologies (ways of being) and epistemologies (ways of knowing) have grown alongside public demands for its regulation and its burgeoning commercial appeal (Chiu, 2009; Willing, Green, \& Pavlidis, 2019). Chiu (2009) notes that while skateboarders redefine the purpose of public space, their transgressions have inflamed reactionary politics of exclusion. Skate parks, for example, provide a place for skaters to practice, but Chiu (2009) contends that their construction is underwritten by a desire to remove skaters (and their perceived antisocial inclinations) from public areas. Chiu (2009) also observes that despite the growing availability of public skate parks, "skaters prefer the natural environment of the street over purposely built spaces" (p. 26). This suggests that while skate parks serve the physical needs of skateboarders, they fail to cultivate the unique orientations skate culture engenders toward land and space. Skate park construction and other municipal attempts to regulate skate culture (such as signs banning skateboarding, the installation of deterrent devices on public structures, and fines) can be conceptualized as exertions of state power designed to control public space and those who use it. The sport's debut at the 2020 Summer Olympics, a potentially momentous event in skateboarding history, should therefore be examined within the historical tension between skate culture and efforts to regulate it. If skateboarding is a pathway to freedom, the notion that success or acceptance can occur only by modifying it to an authority figure's liking is a way to prevent people from pursuing that freedom.

Though the Olympics are anticipated to signify skate culture's transformation from outsider art to mainstream sport (Kassel, 2016), Olympic skateboarding has proven divisive Cultural and Pedagogical Inquiry, Summer 2020, 12(1), pp. 230-243

ISSN 1916-3460 @ 2020 University of Alberta http://ejournals.library.ualberta.ca/index.php/cpi/index 
among skaters (Kassel, 2016; Hawk, 2018). In Kassel's (2016) interviews with both amateur and professional skateboarders, one participant calls the notion of Olympic skateboarding "kind of lame" (p. 1). Another notes that "skateboarding is about having a good time with your friends, not about competing" (p. 2). A third fears that Olympic skateboarding "will erode the cultural values [skateboarders] cherish more than anything" (p. 4).

The discourse surrounding the 2020 Olympics and the history of skateboarding's spatial politics demonstrates how skate culture is a contested space. This contestation partly stems from the pivotal role skateboarding can play in the formation of identities and communities, a role skaters feel is threatened by increasing mainstream influence (Beal and Weldman, 2003). Utilizing the methodology of agential realism, this paper reads narratives of LGBTQ and Indigenous skaters through queer and decolonizing theory to consider how resistance and resurgence occur in skate pedagogy. By analyzing skate cultures built upon the embrace (rather than the erasure) of difference, this paper positions Queer and Indigenous skate pedagogies as sites of knowledge production that presage more just and equitable realities.

\section{Situating Skate Pedagogy}

Skate pedagogy refers to the teaching, learning, and relationship-building that occurs in skateboarding. Learning to skate requires a high level of discipline and the ability to persevere through hardship (Adi, Aditya, \& Citrawati, 2010). Skaters often work on the same maneuvers for years, sustaining a high level of effort and attention even into adulthood and middle age (Willing, 2019). In addition to the self-directed manner in which one learns to skate, skate pedagogy instills the community's "most cherished values" (Kassel, 2016, p. 4). These include orientations toward resistance, rebelliousness, repurposing public space, support for other skaters, and an appreciation for bodily autonomy (Beal, 1995; Chiu, 2009; Lombard, 2010).

Skate pedagogies unsettle dominant constructions of gender, as Hellman (2016) conceives of skateboarding as a site in which participants construct more supportive and sensitive conceptions of masculinity in opposition to mainstream portrayals of men as emotionally stunted and aggressive. Mackay and Dallaire (2014) similarly observe how women participate in skate-centered learning to challenge dominant messages that objectify women and assume that they are hypercompetitive with one another. Skate culture also allows participants to trouble internal and external denigrations of racial and ethnic identities, as exemplified by skaters with racialized identities who challenge misconceptions of black and brown youth (Neumann, 2017; Rockett \& Fine, 2019). The literature demonstrates that skate pedagogy is a context in which dominant narratives can be denounced and dismantled. In these learning contexts, the skateboard itself unlocks possibilities, as riding it encourages a skater to envision novel ways of engaging with discourses, people, and environments (Pyyry \& Tani, 2017; Willing et al., 2019). Diverse forms of learning occur within skate culture, which positions skate pedagogy as a rich field of educational inquiry.

Still, skate pedagogy is not immune to the influence of neoliberal economic ideologies founded upon the hegemonic discourses it ostensibly rails against (Beal, 1995; Brayton, 2005; Lombard, 2010). Beal's (1995) and Lombard's (2010) accounts of corporate incursions into skate culture demonstrate how skateboarding's marketable rebelliousness has piqued the interest of shoe companies, television networks, and the film industry for decades. Lombard (2010) notes, however, that skaters engage with money and power relationally and assuredly. Though 
skaters profess allegiance to skater-owned or core companies, they do not reject corporate partnership by rote and welcome resources so long as sponsors do not exploit or disparage skateboarding (Dinces, 2011). This cautious openness has led to multinational corporations like Nike, Converse, and Adidas engaging with the skateboarding industry, where they enjoy strong reputations largely due to their support of women, queer, and minority skaters (HarrisonCaldwell, 2019).

Despite its antiauthoritarian foundation, skate pedagogy is complex and emerges out of the disparate discourses of rebellion, corporatization, conformity, and non-conformity. This complexity underscores the importance of utilizing relational frameworks to theorize the implications of skate pedagogy. As Brayton's (2005) and Lombard's (2010) analyses of skate texts demonstrate, theorizations of skateboarding which portray it solely as a rebellious act overlook the fact that, for many, the purpose of skateboarding is simply to have fun. A relational theorization of skate pedagogy allows for a more thorough and generative analysis of the entangled and oftentimes contradictory onto-epistemology of skateboarding. This paper applies one such framework, agential realism, to provoke more generative insights into the role of skate pedagogy in the development of queer and decolonizing conceptions of learning.

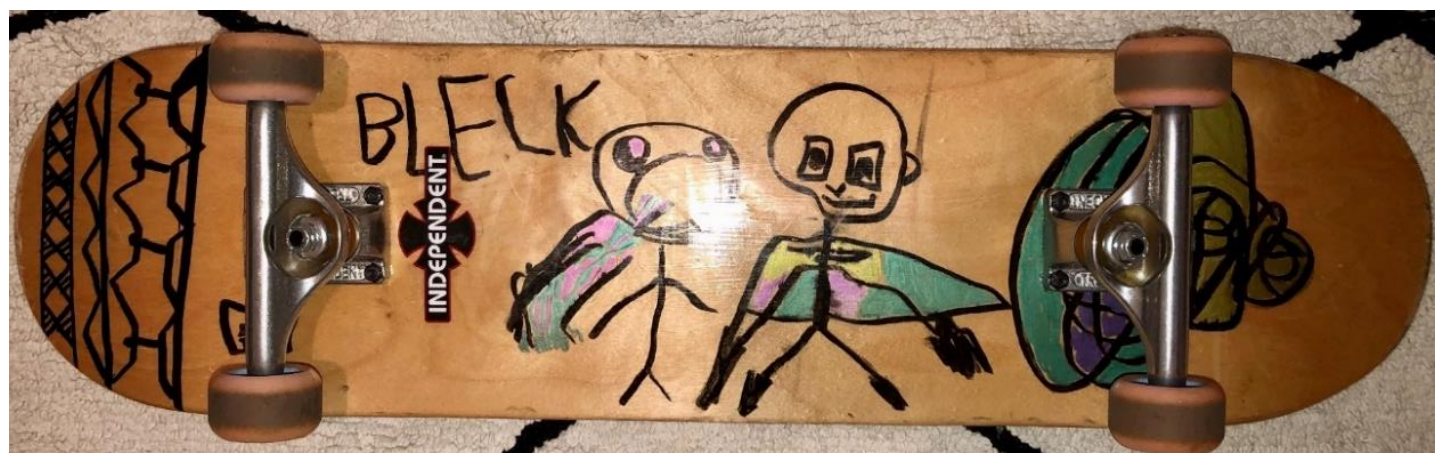

Figure 1. Skateboards are often a reflection of their owners. This board contains an illustration by the rider's son and a design based on Indigenous tattoo traditions in the Philippines (Romero, 2020).

\section{Diffracting Skate Pedagogy}

Barad (2007) defines agential realism as the theory that there is no fixed or indisputable reality and that the universe emerges out of relationships between matter and discourse. For Barad (2007), agencies (such as people, things, ideas, skateboarders, skateboards, skate culture, and skate pedagogy) are intra-active, or come into being only due to their relationships with other agencies and do not pre-exist in finished form. Agential realism calls for flat theorizations which posit that reality consists of events that occur repeatedly and are therefore perceived to be objectively true. Change, as such, occurs by modifying the phenomena associated with these repeated aggregations, often referred to as assemblages, of related agencies (Fox \& Alldred, 2017).

Agential realism is moored in the methodology of diffraction, which Barad (2017) defines as "a matter of reading insights through rather than against each other to make evident the always-already entanglement of specific ideas in their materiality" (p. 64). Skateboarding 
itself is a diffraction, as placing a skateboard between a person and a cityscape alters the affective capacities of both. The skateboard redefines the purpose of a curb, ledge, ramp, or handrail, as well as capabilities of the person riding it. The venerated skater Daewon Song demonstrates this when he skates atop rocks, tree roots, and water, showcasing how skateboarding presents new possibilities for relationships between human beings and their environments. This paper's latter sections explore how adding Queer and Indigenous bodies to those skateboards complicates dominant world orders even further. To foreground this study, in the entanglements of matter and discourse that give rise to skate pedagogy, I begin this paper's analytical sections with a diffractive analysis of skateboarding's most basic move - the ollie.

\section{Of Ollies and Ontology}

The ollie is a foundational maneuver in skateboarding and is a key component of more advanced maneuvers (or "tricks"). At first glance, an ollie looks simply like the rider is jumping into the air while the board follows suit. In reality, the ollie is much more complex. Beginning with all four wheels of the board touching the ground, the rider first pops the tail of the board by extending their back foot downward, which lifts the nose of the board into a vertical position. Shortly after popping the tail, the rider slides their front foot up the length of the board, scraping the edge of their shoe along the board's grip tape, which is typically made of an abrasive material akin to rough-grain sandpaper. This motion will wear holes into the rider's shoes, and these holes are a badge of honor, worn by skaters to as a signifier of authenticity and belonging. This combination of motion, force, and friction allows the rider to flatten out the board in mid-air, at which time they must catch the tail of the board with their back foot, land back on the ground, and roll away.

By breaking the ollie down into its constituent parts, we can observe that it consists of intra-actions between matter, motion, and discourse. Though bringing an ollie into existence depends upon the physical force a skateboarder applies to a skateboard, it is also contingent upon material subjectivities like the texture of the pavement, the size of the skateboard's wheels, and the placement of the rider's feet. The addition of an outward rotation, for example, will transform an ollie into a kick flip. Adding a horizontal spin to a kick flip creates a 360 flip and a 360 flip could be conceived of as a tre flip depending on the skater's sociocultural context. Several tricks performed in succession are a line, and the aggregation of skaters performing lines, the businesses created to serve them, and the grammatological systems that enable them to signify their experiences are all distinct agencies within the assemblages of skateboarding and skate culture.

New materialist research is not limited to observable phenomena, as Barad (2007) calls for the analysis of agential becomings to center considerations put forth by feminist, queer, and critical race theory. Analyses of skateboarding must therefore also consider the political, economic, and sociocultural factors that lead skaters to their boards in the first place. These considerations include the physical, emotional, and intellectual labor of women and LGBTQ skaters who, by having fun, counter, contest, and queer skate culture (Beal, 1996; Carr, 2017). Still, skate culture would not exist if the skateboard itself is removed from the assemblage. Early skateboarders referred to the sport as "street surfing" (IOC, 2017), which is an apt descriptor because the pedagogy of skateboarding parallels Barad's (2004) observation of ocean waves: endlessly emerging, retreating, negating, differentiating, and becoming anew. 
Despite skate pedagogy's liberatory potential, the power and capital associated with skateboarding rests mostly with corporations and regulatory bodies (Dinces, 2011). In addition to bonding over their enjoyment of skateboarding, skaters develop both disdain for authority and compassion for other skaters, partly because they contend with similar attacks on their shared values (MacKay \& Dallaire, 2014; White, 2015). Skate pedagogy parallels punk rock pedagogy in this manner, as it is an "alternative and self-directed educative context in which participants teach, learn, and produce knowledge pertaining to the historical contexts and contemporary experiences of marginalized people" (Romero, 2019, p. 41). The value of skate pedagogy, particularly among marginalized groups, is not derived from the endorsement of the International Olympic Committee or multinational corporations. This paper aims to demonstrate that skateboarding is instead cherished in Queer and Indigenous communities because it offers "that magical feeling you get from knowing that, whatever other identities you own, you're a fucking skater" (Skateism, 2019).

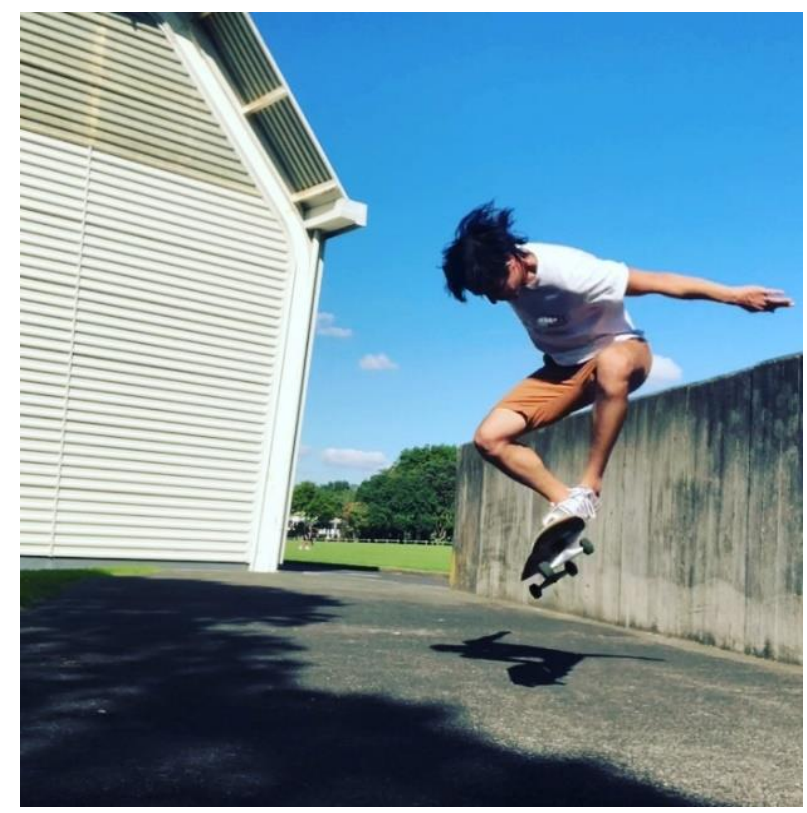

Figure 2. An ollie (Romero, 2019).

\section{A Note on Data Collection}

In the sections that follow, I read texts on gender, decolonization, state power, and skate pedagogy through one another to consider how material conditions informed by these discourses affect and unsettle one another. Data was sourced from two short films: The Mystery of Now and Sibling - London's Queer Skateboarding Crew. I privileged texts which resonated as senseevents, or observations that trigger a researcher's "memories, feelings, [and] world-relations" (Allen, 2018, p. 45) in ways that inspire further inquiry.

Throughout data collection, I often found myself comparing the seemingly infinite possibilities of skate pedagogy with the rigidity of the International Olympic Committee's (IOC) regulations. Reading the data through the work of Indigenous scholars further unearthed parallels Cultural and Pedagogical Inquiry, Summer 2020, 12(1), pp. 230-243 
between the IOC's assumptions of gender and national identity, and the concept of settler futurity, or policies and philosophies that call for "the containment, removal, and eradication of autochthonous peoples" (Goodyear-Ka'ōpua, 2019, p. 86). In contrast, the skate pedagogies documented in these films reflect Goodyear-Ka'ōpua's (2019) conception of Indigenous futurity, "which does not foreclose inhabitation of Indigenous land by non-Indigenous peoples but does foreclose settler colonialism and settler epistemologies" (p. 86). They suggest the possibility of futures founded upon collaboration and compassion instead of racialized capitalism, environmental exploitation, and heteropatriarchy. The following analyses of Queer and Indigenous skate pedagogies demonstrate that the purpose of liberatory education is not to make settler colonialism more inclusive. Rather, liberation means working to eradicate genocidal discourses and establish new ways of being that center our respect for (and responsibilities to) one another, our environment, and our ancestors. Skate pedagogy moreover demonstrates that this work can be fun.

\section{Gender, Space, State Power, and the 2020 Olympics}

Despite its anarchic reputation, skate culture is often a site in which dominant norms rooted in heteronormativity (Rockett \& Fine, 2019), misogyny (Mackay \& Dallaire, 2014), and white supremacy (Brayton, 2005; Atencio, Beal, \& Yochim, 2013) are reproduced. Through its imposition of regulations informed by assumptions of gender essentialism and the legitimacy of state power, Olympic skateboarding has the potential to further inscribe these norms onto skate culture. This potential is evident in the language the IOC uses as the regulatory framework of Olympic skateboarding, which stipulates that the athletes in the skateboarding competition must fit the Commission's definition of men and women.

IOC policy document sorts athletes into gender categories on the basis of "legal sex" (IOC, 2012, p. 1), or the sex printed on one's birth certificate. While the IOC (2012) acknowledges that "human biology... allows for forms of intermediate levels between the conventional categories of male and female" (p. 1), the Committee's regulations reduce the existence of intersex and gender non-conforming athletes to their hormones:

Regulations are designed to identify circumstances in which a particular athlete will not be eligible (by reason of hormonal characteristics) to participate in 2012 OG Competitions in the female category. In the event that the athlete has been declared ineligible to compete in the female category, the athlete may be eligible to compete as a male athlete, if the athlete qualifies for the male event of the sport. (IOC, 2012, p. 1)

The IOC also conflates a narrow and medicalized understanding of gender with a concern for fairness in competition. This concern presupposes that a certain level of hormones will provide an athlete an advantage while ignoring more comprehensive theorizations of gender and sexuality. Such frameworks consider one's physical attributes, the ways others perceive one's gender, and one's own gender performance as constitutive factors of gender identity (Egan \& Perry, 2001). An outcome of this policy is to eliminate the possibility that the Olympic Games might serve as a competitive outlet for gender non-conforming athletes. Olympic skateboarding is similar to formal schooling in this regard, as both enforce understandings of normative bodies and ensure that those who "transgress societal gender norms" are "largely left out" (Rands, 2009, p. 1). The institutionalized exclusion of Olympic skateboarding thus undermines what White (2015) identifies as a foundational component of skate culture - the dynamic relationship between skaters, skateboards, and difference:

Cultural and Pedagogical Inquiry, Summer 2020, 12(1), pp. 230-243

ISSN 1916-3460 @ 2020 University of Alberta

http://ejournals.library.ualberta.ca/index.php/cpi/index 
"...skateboarding in urban environments critiques contemporary cities, and that skateboarding in city streets provides a glimpse of differential spaces, or spaces where differences are valued and celebrated [as]...opposed to the abstract spaces of capitalism, which are homogenous and controlled." (White, 2015, p. 12)

Sibling, a UK queer skateboarding collective, demonstrates how skate culture can foster richer understandings of gender identity. The film Sibling - London's Queer Skateboarding Crew documents a skate pedagogy that recognizes the importance of occupying space in a gender nonconforming body-space that the Olympics would be unwilling to cede. In resistance to the hostility of non-queer skaters, one Sibling member notes that "we did end up taking over one corner of the big room because we were not gonna get any turns if we don't just take over one space" (Sherlock, 2019, n.p.). Paralleling White's (2015) conceptualization of skateboarding as "a form of resistance to spatial [and] racial segregation" (p. 14), Sibling's occupation of contested space at a London skate park could be interpreted as a challenge to the heteronormative and transphobic discourses within that context. The fact that queer skaters must fight for space in a skate park, a place already built to segregate an undesirable population from the public, provides a layer irony.

The documentary then shows Sibling members skating a small ramp in a corner of the park. Few words are spoken but the scene is awash in sense-events. The sounds of wheels rolling over concrete are interspersed with those of wooden tails popping off the floor. These sounds herald the sight of a skateboard spinning in mid-air. A skater with pink hair wearing a sweatsoaked t-shirt hovers over this spinning board, controlling the board while moving in tandem with it. The skaters appear content and focused as they work on tricks and encourage one another. Though this scene lasts only a few seconds, it captures a moment of joyful resistance built upon an embrace of difference. This moment attests to the capacity of skate pedagogy to cultivate compassionate physical, cognitive, and relational skills and orientations. At the center of this potentially transformative learning event is the skateboard. This moment, in fact, would be impossible without it. Underlying this joy is the fact that LGBTQ youth rarely encounter moments like these in school (Allen, 2015).

The entanglements of matter, gender, resistance, and skate culture are further encapsulated by a Sibling member's observation that skateboarding is “just fun, it's just like a stupid sport where you have like a plank with wheels. Why would you be so rigid about, like, gender?" (Sherlock, 2019, n.p.). This question underscores how the skateboard, even when presented as a child's toy, is a diffractive agency. In this skater's account, a "plank with wheels" is a force that reveals the legal endorsement of homophobia, transphobia, and gender-based violence. The prevalence of these discourses even in a 'stupid sport' indicts both the pervasiveness of bigotry and the harm done in places where this bigotry pervades. This statement also provokes another sense-event: a realization that the work of queer collectives, like Sibling, accounted for little in skateboarding's mainstream unveiling. Under the IOC's policies, Olympic skateboarding mandates that queer skaters must again be left alone to claim their space. 


\section{Skate Pedagogy and Indigenous Futurity}

In addition to the IOC's gender regulations, Olympic skateboarding must also conform to the Games' competitive format, which requires athletes to compete on behalf of a national athletic commission, with few exceptions. The national mandate of the IOC regulations precludes participation from nations not recognized by the IOC (such as Niue, New Caledonia, and Iraqi Kurdistan) and by athletes who refuse to tether sport to national politics. Pramod (2008) analyzes the role of the Olympics in welding ideals of human excellence to a robust state apparatus:

The Olympics is acknowledged worldwide as the point of reference for nations' involvement in creating a spirit that could induce human beings to strive for excellence, that is, faster, higher and longer. (p. 112)

As an Olympic sport, skateboarding can no longer be "about having fun with your friends" as the competition transforms it into an exercise in nation-building. Apache Skateboards, a company founded by the artist Douglas Miles, provides a counterpoint to Olympic statism by promoting a skate culture whose strength is not derived from the state but from the relationships between people, matter, and land. The entanglement of skateboarding and Indigenous ontology is showcased in The Mystery of Now, a documentary on the history of Apache Skateboards. In addition to tracing the growth of skate culture in Apache nation, the film functions as a source of sensory data on the affective capacities of decolonizing skate pedagogies, or educative contexts that uplift Indigenous ways of knowing and being through skate culture.

The operations of Apache Skateboards include producing boards with Apache-centered graphics, running a skate shop on the San Carlos Apache reservation, and employing a team of professional Apache and Native skaters. Through his involvement in skateboarding, Miles has observed parallels between skateboarding and Apache warrior culture as he interprets both to require resilience and the willingness to persist in the acquisition of skills and knowledge, in spite of tremendous physical pain (Koht, 2005).

The Mystery of Now documents the pedagogies and praxes embedded in the history and everyday administration of Apache Skateboards as it enters its third decade in operation. The film situates Miles's work and the educative becoming of the skaters recruited for the Apache Skate team within the broader collective endeavor of securing the rematriation of Indigenous lands and the preservation of Indigenous ways of knowing and being (Alfred \& Corntassel, 2005). Endemic to Southern Arizona, the Apache were forcibly exiled and resettled on reservations as a result of the US military confiscation and occupation of Apache land in the late 1800s. Laluk (2017) notes, however, that displacement and genocide have not diluted the Apache sense of inseparability from their lands:

Despite continuous deception, mistreatment, dehumanization, and eventual exile of various Apache groups from southeastern Arizona, Apache communities retain strong social ties through kinship and clan obligations and retain significant associations to their former homelands. (p. 97) 
Laluk (2017) further notes that Apache identity is defined by the relationship Apache have to land and that this relationship becomes more intricate over time. An Apache skateboarder skating on Apache land therefore represents an evolving understanding of the contingent relationality of bodies, land, and matter. This respect for the unfolding bond between land and human vitality underpins Miles's art:

When I look out at San Carlos, I see the power of the past. I see the way Native American people resurrected themselves and why. Because the land is forever. And when you realize the land is forever you realize you are forever. We are forever. (Buchanan, 2019, n.p.)

Miles founded Apache Skateboards as a means of connecting Apache understandings of the interconnectedness of human beings and nature, or what Styres (2019) terms literacies of Land, with the contemporary priorities of Apache youth, or their need for "access to goods and services like everyone else" (Buchanan, 2019, n.p.). Di'Orr Greenwood, a Diné/Navajo woman and Apache team rider, illustrates the role that skate pedagogy plays in her life when she explains that her identity is entwined with a history of trauma. Greenwood asserts that this cycle has ended with her, a fact she credits to her participation in skate culture:

My great grandmother, who's still alive, had to endure such a tremendous amount of pain for me to even live. And that pain followed to my mother. It could've followed me but it didn't. Wherever you're from, it's not gonna dictate where you're going. That's why it's really important for me to connect my culture with skateboard culture. There is a rich, pungent aura that I'm supposed to carry to touch a little girl's heart that needs it and needs to be told hey, you're special. You're gonna change the world. (Buchanan, 2019, n.p.)

Greenwood's words are laid over footage of her weaving lines through freight trucks and skating through desert landscapes. In one scene, Greenwood rides up a bank and performs a shove-it (an ollie with a 180-degree rotation). After landing the shove-it, Greenwood exchanges high-fives with a fellow skater. One can see a fleeting glimpse of the graphic on her board - an Apache warrior wielding a rifle. Other skaters ride boards that are emblazoned with a reminder: You're Skating on Native Land. For Miles and the Apache team, skate pedagogy helps to ensure that emerging generations of Native youth are able to see, hear, feel and know, as Di'Orr Greenwood does, that they will one day change the world.

Through skateboarding, art and activism, Apache Skateboards, its founder, and its riders demonstrate how decolonizing pedagogies trouble "the ways colonist ideologies become normalized within national discourses and internalized among minoritized peoples" (Styres, 2019, p. 32). For Di'Orr Greenwood, skate pedagogy led to her disinvestment from the notion that inherited trauma is inextricable from Native identity. For Douglas Miles, skate pedagogy provides opportunities for Apache youth to develop into self-actualized adults. After the 2020 Olympics have come and gone, Indigenous skaters will continue skating, creating art, and securing Apache self-determination on Apache terms. Miles's work will continue to "help people become aware that Native American art is a living tradition. It is not static, it is definitely not just teepees and headdresses" (Koht, 2005, p. 3). The decolonizing skate pedagogy of Apache Skateboards also underscores the fact that the Apache nation survived the genocidal crusades of the US military. It continues to survive and will live, in the words of Douglas Miles, forever. 


\section{Conclusion}

Skate pedagogy is, ultimately, a pursuit of the freedom to build worlds on our own terms and not those of a state, corporation, or regulatory body. A new materialist reading of Caged Bird illustrates this conception of liberty by eschewing literal interpretations that assume "freedom", for the caged bird means that it too should be able to "claim the sky." The free bird is simply trapped in a different cage, one in which it must participate in a game of declaring ownership over things that belong to no one.

Diffracting skate pedagogy, queer narratives, Indigenous knowledges, and Olympic legitimation portends an unfortunate but foreseeable future: athletes recognized as the world's best skaters will be legally classified men and women competing on behalf of their governments, many of which are guilty of crimes against humanity. Anyone who deviates from the IOC's gendered and statist norms are effectively disqualified from participating in a potentially lucrative form of skateboarding. The IOC's policy therefore centers on what Trinh-Ha Ma calls "...the concept of difference not as a tool of creativity... but as a tool of segregation, to exert power on the basis of racial and sexual essences. The apartheid kind of difference" (as quoted in Barad, 2014, p. 169). Olympic skateboarding is moreover predicated upon Barad's (2014) conception of colonizing logic, in which the self comes into being by removing, resettling and exterminating the other.

Yet, Olympic skateboarding is just one form of skate culture. Though the Olympics are only accessible to a small group of approvable athletes, there is no combination of laws, street signs, or obstacles that can prevent a person from riding a skateboard. Once astride that board, there is no predicting what a skater will learn about themselves and their relationship to the ground beneath their wheels. The ongoing commodification of skateboarding thus presents skate culture with an opportunity to recognize the subaltern discourses emerging from within it, inviting all skaters to participate in a new paradigm that offers collaboration instead of competition and support, instead of suffering. As Angelou writes, these cries cannot go unheeded: and his tune is heard / on the distant hill / for the caged bird / sings of freedom 


\section{References}

Adi, E., Aditya, I. G. M. K., \& Citrawati, M. (2010). Learn street skateboarding through 3D simulations of angle rotations. Journal of Information Technology Education, 9, 217+.

Allen, L. (2015) Picturing queer at school. Journal of LGBT Youth, 12(4), 367-384. doi:10.1080/19361653.2015.1077766

Allen, L. (2018). Sexuality education and new materialism: Queer things. New York: Palgrave MacMillan.

Alfred, T. and Corntassel, J. (2005). Being Indigenous: Resurgences against contemporary colonialism. Government and Opposition, 40, 597-614. doi:10.1111/j.1477-7053.2005.00166.x

Atencio, M., Beal, B., \& Yochim, E. (2013). "It ain’t just black kids and white kids": The representation and reproduction of authentic "skurban" masculinities. Sociology of Sport Journal, 30, 153-172.

Barad, K. (2007). Meeting the universe halfway: Quantum physics and the entanglement of matter and meaning. Durham: Duke University Press.

Barad, K. (2014). Diffracting diffraction: Cutting together-apart. Parallax, 20(3), 168-187.

Beal, B. (1995). Disqualifying the official: An exploration of social resistance through the subculture of skateboarding. Sociology of Sport Journal, 12, 252-267.

Beal, B. and Weldman, L. (2003). Authenticity in the skateboarding world. In R. Rinehart \& S. Sydnor (Eds.), To the extreme: Alternative sports inside and out. Albany, NY: State University of New York Press, 337-352.

Buchanan, A. (2019). The Mystery of Now [Motion Picture]. USA: National Geographic.

Brayton S. (2005). 'Black-Lash': Revisiting the 'White Negro' through skateboarding. Sociology of Sport Journal, 22(3), 356-372.

Carr, J. (2017). Skateboarding in dude space: The roles of space and sport in constructing gender among adult skateboarders. Sociology of Sport Journal, 34(1), 25-34.

Chiu, C. (2009). Contestation and conformity: Street and park skateboarding in New York City Public Space. Space and Culture, 12(1), 25-42. https://doi.org/10.1177/1206331208325598

Dinces, S. (2011). 'Flexible Opposition': Skateboarding subcultures under the rubric of late capitalism. The International Journal of the History of Sport, 28(11), 1512-1535. doi:10.1080/09523367.2011.586790

Fox, N., \& Alldred, P. (2017). Sociology and the new materialism: Theory, research, action. Los Angeles: Sage.

Cultural and Pedagogical Inquiry, Summer 2020, 12(1), pp. 230-243

ISSN 1916-3460 (C) 2020 University of Alberta

http://ejournals.library.ualberta.ca/index.php/cpi/index 
Freire, P. (2018). Pedagogy of the oppressed. New York: Bloomsbury.

Goodyear-Ka'ōpua, N. (2019). Indigenous Oceanic futurities: Challenging settler colonialisms and militarization. In L. Smith, E. Tuck \& K. W. Yang \& (Eds.), Indigenous and decolonizing studies in education: Mapping the long view. New York: Routledge.

Harrison-Caldwell, M. (May 31, 2019). Let's put this shit to bed. Skateism. Retrieved from: https://www.skateism.com/lets-put-this-shit-to-bed

Hawk, T. (October 9, 2018). Thoughts of Olympic skateboarding. Medium. Retrieved from: https://medium.com/s/story/skateboarding-will-be-in-the-olympics-in-less-than-twoyears-4bdcb8734061

Hellman, A. (2016). 'Skateboarding is like dancing': Masculinity as a performative visual culture in art education. International Journal of Education Through Art, 12(3), 327-344.

International Olympic Committee (October 19, 2017). History of skateboarding at the Olympic Games (IOC Publication). Retrieved from: https://stillmed.olympic.org/media/Document\%20Library/OlympicOrg/FactsheetsReference-Documents/Games/OG/History-of-sports/Reference-document-SkateboardingHistory-at-the-OG.pdf\#ga=2.140273971.1204377350.1576207530-1901886707.1576207530

International Olympic Committee. (June 22, 2012). IOC Regulations on Female Hyperandrogenism (IOC Publication). Retrieved from: https://stillmed.olympic.org/Documents/Commissions_PDFfiles/Medical_commission/2012 -06-22-IOC-Regulations-on-Female-Hyperandrogenism-eng.pdf

Kassel, N. (August 18, 2016). We asked skaters how they feel about skateboarding making the 2020 Olympics. Vice. Retrieved from: https://www.vice.com/en_uk/article/nny3nm/weasked-skaters-how-they-feel-about-skateboarding-making-the-2020-olympics

Koht, P. (March 30, 2005). San Carlos street style rez. Metroactive. Retrieved from: http://www.metroactive.com/papers/cruz/03.30.05/apache-0513.html

Laluk, N. C. (2017). The indivisibility of land and mind: Indigenous knowledge and collaborative archaeology within Apache contexts. Journal of Social Archaeology, 17(1), 92-112. https://doi.org/10.1177/1469605317690082

Lombard, K. (2010). Skate and create/skate and destroy: The commercial and governmental incorporation of skateboarding, Continuum, 24(4,) 475-488. doi:10.1080/10304310903294713

MacKay, S., \& Dallaire, C. (2014). Skateboarding women: Building collective identity in cyberspace. Journal of Sport and Social Issues, 38(6), 548-566.

Neumann, S. (April 3, 2017). 15 Years of APACHE skateboards links Indigenous and skate cultures. Vice. Retrieved from: https://www.vice.com/en_us/article/433q8q/15-years-of-apacheskateboards-links-indigenous-and-skate-cultures 
Pramod, C. R. (2008). The 'Spectacle' of the Beijing Olympics and the dynamics of state-society relationship in PRC. China Report, 44(2), 111-137. https://doi.org/10.1177/000944550804400202

Pyyry, N. \& Tani, S. (2017). More-than-human playful politics in young people's practices of dwelling with the city. Social \& Cultural Geography. doi:10.1080/14649365.2017.1358823

Rands, K. (2009). Considering transgender people in education: A gender-complex approach. Journal of Teacher Education, 60(4), 419-431. https://doi.org/10.1177/0022487109341475

Rockett, D. \& Fine, C. (September 17, 2019). Chicago 'black girl skate crew' offers skateboard sisterhood for women of color and queer community. Chicago Tribune. Retrieved from: https://www.scribd.com/article/426220802/Chicago-black-Girl-Skate-Crew-OffersSkateboard-Sisterhood-For-Women-Of-Color-And-Queer-Community

Romero, N. (2020). Punx up, bros down: Defending free speech through punk rock pedagogy. Educational Philosophy and Theory. doi:10.1080/00131857.2020.1738923

Romero, N. (2019). Pilipinx becoming, punk rock pedagogy, and the new materialism. The International Education Journal: Comparative Perspectives, 18(2), 40-54.

Romero, N. (2016). Rise above: Filipina/o-American studies and punk rock pedagogy. In D. Sandoval, T. Buenavista, J. Marin \& A. Ratcliff (Eds.), The new culture wars in ethnic studies (pp. 117-133). Santa Barbara, CA: Praeger.

Sherlock, R. (2019). Sibling, London's queer skateboarding crew [Motion Picture]. Greece: Skateism.

Styres, S. (2109). Literacies of Land: Decolonizing narratives, storying, and literature. In L. Smith, E. Tuck \& K. W. Yang (Eds.), Indigenous and decolonizing studies in education: Mapping the long view. New York: Routledge.

White, K. (2015). "We out here": Skateboarding, segregation and resistance in the Bronx. ProQuest Dissertations and Theses.

Willing, I., Green, B., \& Pavlidis, A. (2019). The 'boy scouts' and 'bad boys' of skateboarding: A thematic analysis of the Bones Brigade. Sport in Society, 23(5), 832-846. doi:10.1080/17430437.2019.1580265

Willing, I., Bennett, A., Piispa, M., \& Green, B. (2019). Skateboarding and the 'tired generation': Ageing in youth cultures and lifestyle sports. Sociology, 53(3), 503-518. doi:10.1177/0038038518776886

Worldskate. (n.d.). Olympic qualifying system. World Skate. Retrieved from: http://www.worldskate.org/olympic-qualifying-system/qualification-system.html 